\title{
Membrane and intracellular effects of ultraviolet irradiation with Hoechst 33342 on bovine secondary oocytes matured in vitro
}

\author{
L. C. Smith \\ Centre de Recherche en Reproduction Animale, Faculté de Médecine Vétérinaire, Université de \\ Montréal, Saint-Hyacinthe, Québec, J2S 7C6, Canada
}

\begin{abstract}
Ultraviolet (UV) irradiation in combination with the bisbenzimide stain Hoechst 33342 has been used to visualize the chromosomes before removal of oocytes to be used as cytoplasmic hosts for embryo nuclear transplantation. Short term effects of UV irradiation on the cytoplasmic viability of bovine oocytes matured in vitro were assessed by performing membrane and intracellular studies at 2 and $20 \mathrm{~h}$ after exposure to UV irradiation for 0 , 30 or $60 \mathrm{~s}$. At the membrane level, loss of integrity was shown by increased lysis and increased retention of the fluorescein diacetate dye in oocytes exposed to $60 \mathrm{~s}$ of UV irradiation and uptake of methionine was higher in both irradiated groups. At the intracellular level, methionine incorporation into protein was 5.8 times higher in controls than in oocytes exposed to UV irradiation for $60 \mathrm{~s}$ and there was a marked difference in the pattern of protein synthesis. Some changes in protein synthesis were also found in oocytes after 30 s exposure. Moreover, high levels of fluorescence with the dye rhodamine 123 at $20 \mathrm{~h}$ after exposure indicated large increases in mitochondrial membrane potential in both groups of UV-irradiated oocytes. Together, these findings indicate that exposure to UV irradiation for periods as short as $60 \mathrm{~s}$ causes alterations to both membrane and intracellular components of bovine oocytes matured in vitro. It is concluded that care must be taken when using this methodology to visualize or destroy metaphase chromosomes during enucleation in the embryo cloning protocol.
\end{abstract}

\section{Introduction}

Nuclear transplantation, and its application to the production of genetically identical mammals, has the potential to become an important procedure for studying nuclear-cytoplasmic interactions in embryos and to improve the rate of genetic gain in animal production (Bondioli et al., 1990; Robl and Stice, 1990). Lack of knowledge in some of the many steps involved in the procedure have led to a low overall efficiency of approximately $1-6 \%$ in producing offspring (Yang, 1991). One of these steps involves the removal of the genetic material contained within the recipient oocyte (enucleation). Total chromosomal removal is necessary to (1) eliminate any genetic contribution of the host cytoplasm and thus assure maximal similarity between cloned animals and (2) avoid ploidy abnormalities with its deleterious consequences to normal development. Owing to the presence of dense cytoplasmic granules in the oocytes of most domestic species, metaphase chromosomes cannot be readily visualized, a factor which causes about 30\% errors in enucleation (Prather et al., 1987; Prather et al., 1989; Smith and Wilmut, 1989).

Ultraviolet irradiation (UV) and DNA-specific binding stains have been used to visualize oocyte and embryonic nuclei, and to assess enucleation efficiency after micromanipulation (Critser and First, 1986; Prather et al., 1989; Smith and Wilmut, 1989).

Received 27 July 1992.
Studies in mice have shown that the pronuclei and the cytoplasm have different sensitivities to Hoechst staining and UV irradiation (Tsunoda et al., 1988). Whereas developmental potential of pronuclei was completely blocked after $20-30 \mathrm{~s}$ exposure to UV, developmental arrest due to cytoplasmic effects could be detected only with exposures of more than $30 \mathrm{~s}$. Moreover, a recent report in cattle has shown that exposure to UV irradiation for $10 \mathrm{~s}$ has no effect on embryo viability and production of live calves (Westhusin et al., 1992).

Destruction without the removal of oocyte metaphase chromosomes has been attempted in rabbits using exposure to UV irradiation for 3 min (Yang et al., 1990). Culture of the reconstituted embryos in vitro showed a decrease in the viability when using irradiated oocytes, suggesting deleterious cytoplasmic effects of the longer exposures. Studies on the effects of UV irradiation in Xenopus eggs, where functional enucleation is a normal practice, showed that exposure of eggs for periods of between 15 and $50 \mathrm{~s}$ was without effect (Gurdon, 1960). However, 30\% abnormal development was obtained when using a 30-80 $\mathrm{s}$ exposure suggesting that there is some cytoplasmic effect. Further studies are required to improve the current techniques for enucleating oocytes for use in nuclear transplantation. The following study was undertaken to verify the effects of UV irradiation on membrane and intracellular components of in vitro matured bovine oocytes stained with Hoechst 33342. 


\section{Materials and Methods}

\section{Production of secondary oocytes}

Bovine ovaries were collected at a local abattoir and transported to the laboratory in phosphate-buffered saline (PBS; $\mathrm{pH}$ 7.4), supplemented with 100 iu penicillin $\mathrm{ml}^{-1}$ and $100 \mu \mathrm{g}$ streptomycin $\mathrm{ml}^{-1}$ (Pen/Strep; Gibco, Grand Island, NY) in an insulated container. At the laboratory, ovaries were washed twice in PBS and the contents of non-haemorrhagic follicles with a diameter between 1 and $5 \mathrm{~mm}$ were aspirated using a 20 gauge needle. Cumulus-oocyte complexes with complete cumulus layers and homogeneous cytoplasm were selected and washed twice in Hepes-buffered tissue culture medium 199 (TCM 199, Gibco) and placed into bicarbonate-buffered TCM 199 (Gibco) supplemented with $10 \%$ heat-treated oestrous cow serum (ECS) for maturation. Groups of approximately 100 cumulus-oocyte complexes supplemented with granulosa cells were placed in $\mathrm{I} \mathrm{ml}$ wells and cultured for $26-28 \mathrm{~h}$ at $38.5^{\circ} \mathrm{C}$ in a humidified atmosphere of $5 \% \mathrm{CO}_{2}$ in air. At the end of the maturation period, expanded cumulus-oocyte complexes were placed in $\mathrm{Ca}^{2+}$ - and $\mathrm{Mg}^{2+}$-free Ham's medium (Gibco) supplemented with 300 iu bovine testis hyaluronidase $\mathrm{ml}^{-1}$ (Sigma, St Louis, MO) and vigorously shaken for $3 \mathrm{~min}$ to remove the cumulus cells. Denuded oocytes with a homogeneous cytoplasm were selected for further use in experiments.

\section{Staining, ultraviolet irradiation and activation protocols}

Unless specified, oocytes to be exposed to UV were incubated in bicarbonate-buffered TCM199 with $5 \mu \mathrm{g}$ Hoechst stain $33342 \mathrm{ml}^{-1}$ (bisbenzimide trihydrochloride; Sigma) for $30 \mathrm{~min}$ at $38.5^{\circ} \mathrm{C}$. After staining, the oocytes were washed in Hepesbuffered TCM199 and placed in a glass chamber for fluorescence and irradiation studies. Oocytes were randomly distributed into three groups and exposed to $55 \mathrm{nW}$ of UV irradiation for $0 \mathrm{~s}$ (control group), $30 \mathrm{~s}$ or $60 \mathrm{~s}$. The UV irradiation dose was measured using a photodetector (model 818-UV: Newport Corp., CA) with an optical power meter (model 840: Newport Corp.). Irradiation was performed on individual oocytes with a $\times 40$ objective (DIC LWD: Nikon, Tokyo) on an inverted microscope equipped with Epi-fluorescence (TMD-Diaphot: Nikon), a $50 \mathrm{~W}$ mercury lamp (Philips, Germany) and an ultraviolet filter block (330-380 nm excitation and $420 \mathrm{~nm}$ emission, UV-2A: Nikon). After UV irradiation, oocytes were removed from the glass chamber and placed for a 10 min equilibration period in a low electrolyte solution of $0.3 \mathrm{~mol}$ mannitoll ${ }^{-1}, 0.1 \mathrm{mmol} \mathrm{MgSO} \mathrm{I}^{-1}$ and $0.05 \mathrm{mmol} \mathrm{CaCl}_{2} \mathrm{l}^{-1}$ in water (Willadsen, 1986). Oocytes were placed in an electrofusion chamber containing activation medium and positioned between two parallel platinum electrodes $200 \mu \mathrm{m}$ apart. Activation was produced by a $20 \mathrm{~V}$ square direct current pulse $\left(1.0 \mathrm{kV} \mathrm{cm}^{-1}\right)$ with $70 \mu \mathrm{s}$ duration (Electro Cell Manipulator 200: BTX, CA). After the activation stimulus, oocytes were removed from the electrofusion chamber, washed three times in TCM 199 and incubated until further analysis. Control and UV irradiated oocytes were examined either after $2 \mathrm{~h}$ to determine the most immediate effects or after $20 \mathrm{~h}$ to determine the progression of these effects. A small group of oocytes was examined before the activation stimulus to determine the effects of this procedure on the different aspects of oocyte viability.

\section{Amino acid uptake and incorporation of oocytes}

Oocytes were washed in modified Tyrode's medium, supplemented with $0.6 \%$ BSA (Fraction V; Sigma), lactate, pyruvate and gentamicine (TALP, as described by Parrish et al. (1986)). After washing, oocytes were incubated for $2 \mathrm{~h}$ in $50 \mu \mathrm{l}$ drops of TALP containing $\mathrm{L}^{-35}{ }^{35}$ ) methionine $\left(1 \mathrm{mCi} \mathrm{ml}^{-1},>800 \mathrm{Ci}\right.$ $\mathrm{mmol}^{-1}$; Amersham, Canada). After incubation, they were washed free of radiolabelled precursor by three transfers through TALP and a final wash in PBS to remove protein present in the medium. Washed individual oocytes were disrupted by adding $50 \mu \mathrm{l}$ SDS dissociation buffer $(62.5 \mathrm{mmol}$ Tris- $\mathrm{HCl}$ $1^{-1}, \mathrm{pH} 6.8$, containing $2 \% \mathrm{w} / \mathrm{v}$ SDS, $10 \%$ glycerol and $5 \% \mathrm{v} / \mathrm{v}$ 2-mercaptoethanol) followed by heating at $95^{\circ} \mathrm{C}$ for $15 \mathrm{~min}$. Uptake of L- $\left[{ }^{35} \mathrm{~S}\right]$ methionine by individual oocytes was assayed by counting $4 \mu \mathrm{l}$ of SDS-dissociated extracts in Aquasol scintillation cocktail (New England Nuclear, Boston). Incorporation of acid precipitable protein was measured in individual oocytes by transferring $4 \mu \mathrm{l}$ of the same SDS-dissociated extracts onto Whatman GF/C filters. Dried filters were washed with $20 \mathrm{ml}$ $10 \%$ trichloroacetic acid and $10 \mathrm{ml}$ absolute ethanol, dried, and counted in the scintillation cocktail.

\section{One-dimensional SDS-PAGE and densitometric analysis}

Individual oocytes obtained $20 \mathrm{~h}$ after the activation stimulus were used in this experiment. Radiolabelled proteins were separated and resolved by SDS-PAGE carried out on an electrophoresis cell (Mini-Protean II: BioRad, Richmond, CA) attached to a power supply (PS2500 DC: Hoefer Scientific Inst., San Francisco) according to the method of Laemmli (1970). The remaining SDS-dissociated individual oocyte extracts were loaded onto $12 \%$ slab polyacrylamide gels that were $0.75 \mathrm{~mm}$ thick. After electrophoresis, the gels were stained and treated with an autoradiography enhancer $\left(\mathrm{En}^{3} \mathrm{Hance}\right.$ New England Nuclear, Boston), dried and then exposed to pre-flashed X-ray film at $-70^{\circ} \mathrm{C}$ for 3 weeks. Densitometric analysis was performed using a laser densitometer (UltraScan XL: Pharmacia, Sweden) and computer analysis (GelScanXL Software Package: Pharmacia).

\section{Rhodamine 123 staining and fluorescence quantification}

The purified laser dye rhodamine 123 (R123; Sigma) was dissolved in distilled water at a concentration of $1 \mathrm{mg} \mathrm{ml}^{-1}$ and subsequently diluted to $10 \mu \mathrm{g} \mathrm{ml}^{-1}$ in TCM199 for incubation (Johnson et al., 1980). Oocytes were incubated for $30 \mathrm{~min}$ at $38.5^{\circ} \mathrm{C}$ after which they were washed several times in TCM199 without R123 and examined by epifluorescent illumination using a green filter block $(510-560 \mathrm{~nm}$ excitation and $610 \mathrm{~nm}$ emission; G-2A: Nikon). Quantitative measurement of the emitted fluorescence from individual oocytes was obtained using a microphotometry system (System PI: Nikon) attached to the microscope.

\section{Fluorescein diacetate (FDA) staining and fluorescence quantification}

A stock solution of $5 \mathrm{mg} \mathrm{FDA} \mathrm{ml}^{-1}$ (Sigma) in acetone was prepared and stored at $-20^{\circ} \mathrm{C}$. Just before use, a stock solution 

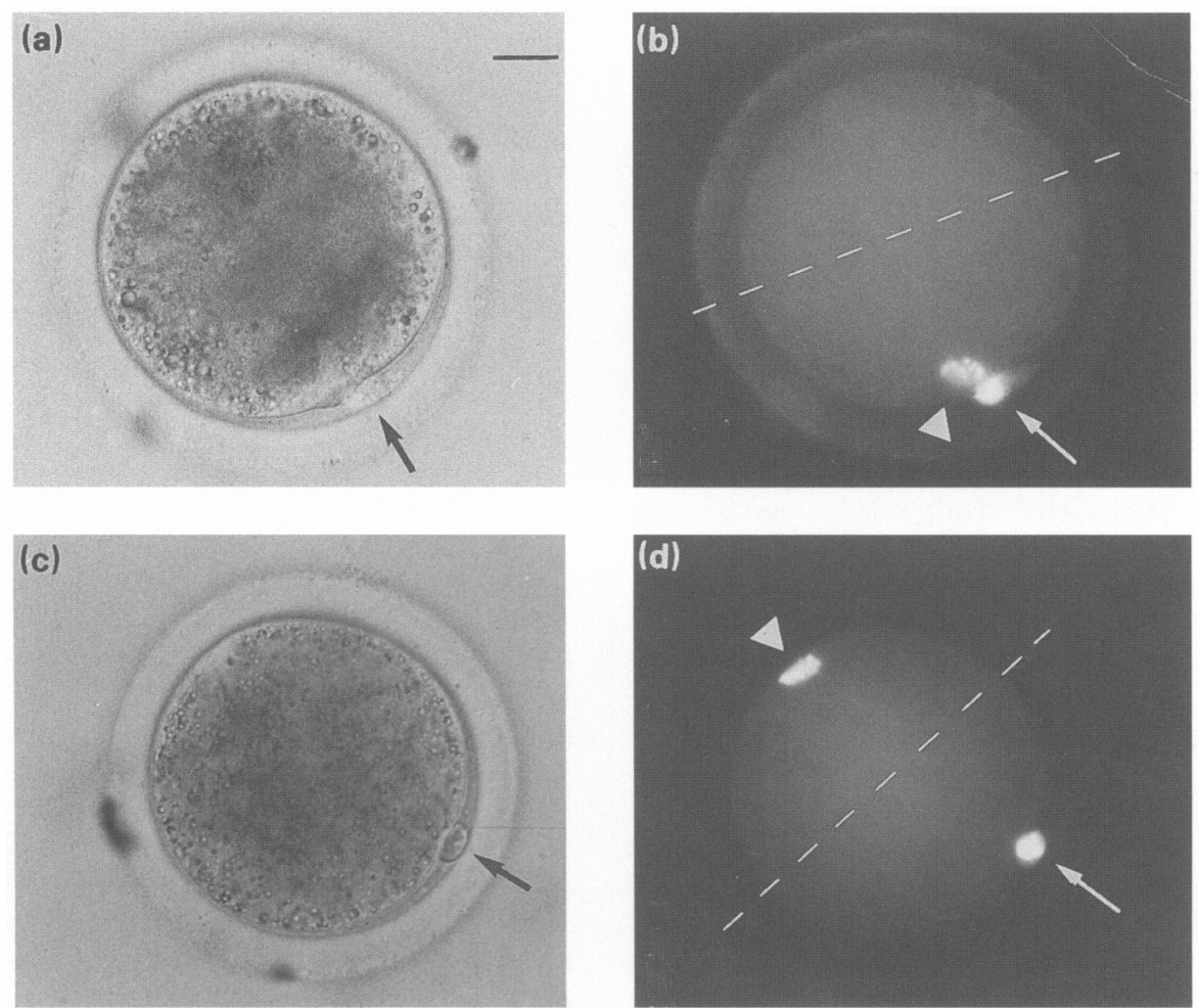

Fig. 1. Bovine secondary oocytes matured in vitro after cumulus removal and staining with the bisbenzimide dye Hoechst 33342. (a) and (b) show a single oocyte with polar body located close to the metaphase chromosomes; (c) and (d) show another oocyte with polar body positioned away from the metaphase chromosomes before and during excitation with UV light ( $365 \mathrm{~nm}$ main wavelength), respectively. Arrows indicate first polar bodies; arrowheads indicate metaphase chromosomes; the dotted line separates the oocyte into two hemispheres according to the position of the metaphase chromosomes. Bar $=20 \mu \mathrm{m}$.

of $0.5 \mu \mathrm{ml}^{-1}$ in PBS was prepared giving a final concentration of $2.5 \mu \mathrm{g} \mathrm{FDA} \mathrm{ml}{ }^{-1}$ (Mohr and Trounson, 1980). Oocytes were incubated in this solution for I min at room temperature after which they were washed several times in PBS. After incubation at room temperature for $10 \mathrm{~min}$, the oocytes were examined by epifluorescent illumination using a blue filter block (450$490 \mathrm{~nm}$ excitation and $520 \mathrm{~nm}$ emission; B-2A: Nikon). Quantitative measurements of the emitted fluorescence from individual oocytes were obtained using the same microphotometric system described for R123.

\section{Statistical analysis}

Data collected from individual oocytes grouped into three to five replications were assembled for statistical analysis and analysed using the General Linear Model procedure. Individual means were compared using Duncan's multiple range test (SAS Inc., Cary, NC). Data on the proportion of oocytes lysed after UV irradiation were analysed by $\chi^{2}$ test.

\section{Results}

After removing the cumulus cells from the cumulus-oocyte complexes, a total of 507 in vitro matured bovine oocytes were

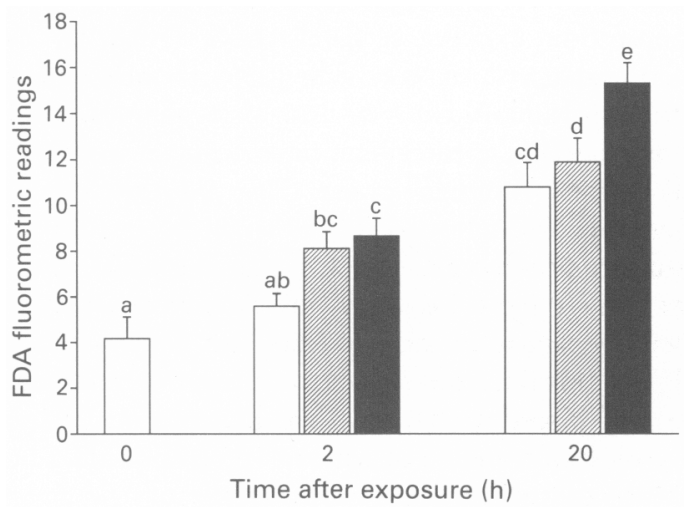

Fig. 2. Intensity of emission from the fluorescein diacetate (FDA) dye retained in oocytes exposed to UV irradiation for periods of $O(\square), 30$ $(\square)$ or $60 \mathrm{~s}(\boldsymbol{D})$ and measured at 0,2 and $20 \mathrm{~h}$ after exposure. Values with different letters are significantly different $(P<0.05)$.

considered suitable, selected and randomly allocated for use in these experiments. The position of the first polar body within the perivitelline space and its relationship to the metaphase chromosomes was recorded in most UV irradiated oocytes (Fig. 1). Proper positioning was possible by rotating the oocyte to place both polar body and metaphase chromosomes on the same focal plane. From a total of 220 oocytes examined, 158 


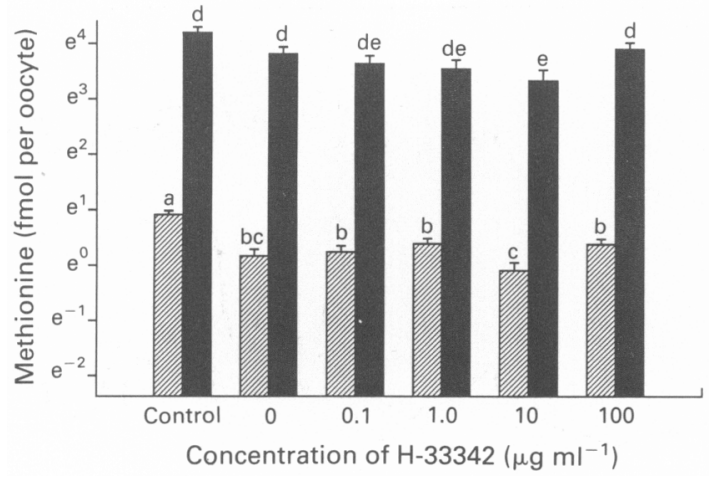

Fig. 3. Incorporation $(\mathbb{Z})$ and uptake $(\boldsymbol{Q})$ of $\left[{ }^{35}\right.$ S $]$ methionine by control non-exposed oocytes and oocytes exposed to $30 \mathrm{~s}$ of UV after incubation with different concentrations of $\mathrm{H}-33342$ (range from 0 to $100 \mu \mathrm{g} \mathrm{ml}^{-1}$ ). Values with different letters are significantly different $(P<0.05)$.

$(72 \%)$ had the polar body located in the same hemisphere, whereas 62 oocytes $(28 \%)$ had polar bodies located in the hemisphere opposite to the metaphase chromosomes.

Oocytes were considered to have undergone lysis either when no plasma membrane was observed or when the plasma membrane appeared rough and fragmented under differential interference contrast optics. Loss of membrane integrity by lysis was observed in 16 out of a total of 149 oocytes $(11 \%)$ in the control group, eight out of 125 oocytes (7\%) exposed to $30 \mathrm{~s}$, and 45 out of 145 oocytes ( $31 \%$ ) exposed to 60 s of UV irradiation. The proportion of lysis was significantly higher $(P<0.01)$ in the $60 \mathrm{~s}$ group than in both $30 \mathrm{~s}$ and untreated control groups which did not differ from each other $(P>0.05)$. The presence of lysed oocytes in the control group indicated that either the mannitol solution or the electric stimulus or both were causing some loss in membrane integrity.

Accumulation of fluorescein diacetate (FDA) in oocytes increased significantly with time and after prolonged exposure to UV irradiation. A total of 210 non-lysed oocytes were analysed for FDA in three replicates with an average of 30 oocytes per experimental group (Fig. 2). Although slightly increased, the amounts of FDA in oocytes exposed for $30 \mathrm{~s}$ were not significantly different from that in controls at $2 \mathrm{~h}$ after irradiation $(P>0.05)$. However, the amount of FDA found in oocytes exposed for $60 \mathrm{~s}$ was significantly higher than that in controls at this time $(P<0.05)$. A large increase in FDA accumulation was observed at $20 \mathrm{~h}$ in control and UV irradiated groups. At this time, the control and $30 \mathrm{~s}$ groups did not differ $(P>0.05)$, but oocytes exposed to $60 \mathrm{~s}$ of UV irradiation had significantly more FDA accumulated in the cytoplasm $(P<0.05)$.

Uptake and incorporation of radiolabelled methionine were analysed at $20 \mathrm{~h}$ after activation in a total of 24 oocytes used in protein synthesis analysis. Counting of $\left.{ }^{35} \mathrm{~S}\right]$ methionine in the SDS-dissociated extracts from individual oocytes indicated an average uptake during the $2 \mathrm{~h}$ incubation of $35.7 \pm 1.8 \mathrm{fmol}$ by the non-exposed controls, $52.7 \pm 7.0 \mathrm{fmol}$ by the group exposed to UV irradiation for $30 \mathrm{~s}$ and $51.8 \pm 7.5 \mathrm{fmol}$ of methionine by the oocytes exposed to $60 \mathrm{~s}$ of UV irradiation. Both UV irradiated groups had significantly higher uptake than controls $(P<0.05)$. Incorporation of $\left.{ }^{35} \mathrm{~S}\right]$ methionine into precipitable protein was substantially affected by a long exposure to UV irradiation. Counting of the radiolabelled precursor in the precipitable protein fraction of oocytes indicated an average incorporation during the $2 \mathrm{~h}$ incubation of $2.9 \pm$ $0.2 \mathrm{fmol}$ in the control group, $2.1 \pm 0.4 \mathrm{fmol}$ in the group exposed to UV irradiation for $30 \mathrm{~s}$ and $0.5 \pm 0.1 \mathrm{fmol}$ $\left[{ }^{35}\right.$ S $]$ methionine in the oocytes exposed to $60 \mathrm{~s}$ of UV irradiation. Incorporation in oocytes after $60 \mathrm{~s}$ exposure was significantly lower than in control and $30 \mathrm{~s}$ groups $(P<0.05)$. A subsequent experiment was performed to analyse the effect of a standard dose of UV $(30 \mathrm{~s})$ both on unstained oocytes and using different concentrations of $\mathrm{H}-33342$ (Fig. 3). With the exception of the highest concentration $\left(100 \mu \mathrm{g} \mathrm{m}^{-1}\right)$, in which medium saturation and precipitation of stain were noticed, uptake of radiolabelled methionine decreased gradually and significantly by increasing the concentration of the stain. There was no difference between unexposed oocytes and oocytes exposed to $\mathrm{UV}$ in the absence of $\mathrm{H}-33342$ or at concentrations up to $1 \mu \mathrm{g}$ $\mathrm{ml}^{-1}$. However, incorporation of radiolabelled methionine decreased substantially after exposure to UV regardless of whether the stain was present. The lowest incorporation was observed using $\mathrm{H}-33342$ at a concentration of $10 \mu \mathrm{g} \mathrm{ml}^{-1}$. These results indicate that although UV irradiation without the stain will not affect methionine uptake, this level of exposure will affect protein synthesis in oocytes. A synergistic effect of $\mathrm{H}-33342$ was detected for uptake and incorporation at $10 \mu \mathrm{g}$ $\mathrm{ml}^{-1}$.

Qualitative analysis by one-dimensional SDS-PAGE of proteins that are synthesized at $20 \mathrm{~h}$ after activation showed marked differences between both irradiated groups and controls. Owing to the large variation in levels of incorporation between control and UV irradiated oocytes, direct visual analysis of autoradiograms provided limited information on the different patterns found in each group (Fig. 4a). Fine details of these changes were better visualized from densitometric scans of the same autoradiogram (Fig. 4b) and could be classified into two categories. First, protein bands present in the control group and in the group exposed to UV irradiation for $30 \mathrm{~s}$ that were not present in oocytes exposed to $60 \mathrm{~s}$ of irradiation $(76,100$ and $120 \mathrm{kDa}$ ) and second, proteins not present in controls which appeared after irradiation. In this category were proteins present in both the 30 and $60 \mathrm{~s}$ exposure group $(69,82$ and $104 \mathrm{kDa}$ ) and others, only observed in the $60 \mathrm{~s}$ group (42 and $124 \mathrm{kDa}$ ).

Fluorometric monitoring of mitochondrial membrane potential with the laser dye rhodamine 123 (R123) on individual oocytes was significantly higher and more variable after UV irradiation (Fig. 5). A total of 194 oocytes was analysed in three replicates. Although the $60 \mathrm{~s}$ group oocytes retained the amount of RI23 fluorescence, the average readings for control and $30 \mathrm{~s}$ irradiated oocytes seemed to decrease slightly after $2 \mathrm{~h}$ $(P>0.05)$. However, at $20 \mathrm{~h}$ after irradiation, significantly more R123 fluorescence was observed in groups irradiated for both 30 and $60 \mathrm{~s}(P<0.05)$.

\section{Discussion}

The present study shows that in vitro matured bovine oocytes stained with the bisbenzimide dye, Hoechst 33342, and 
(a)

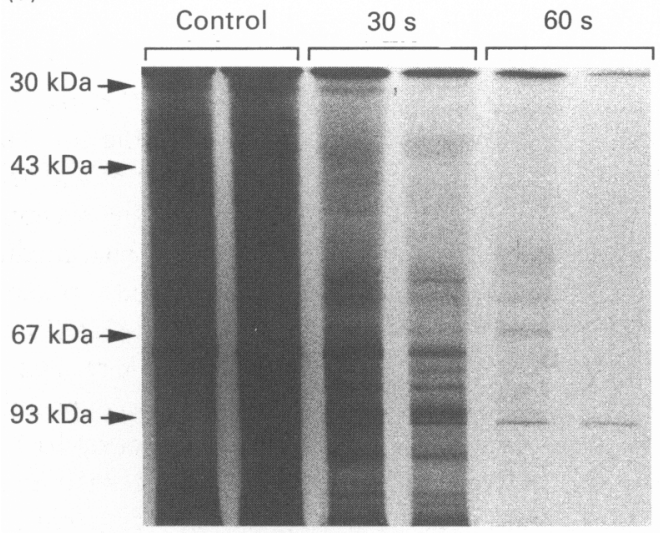

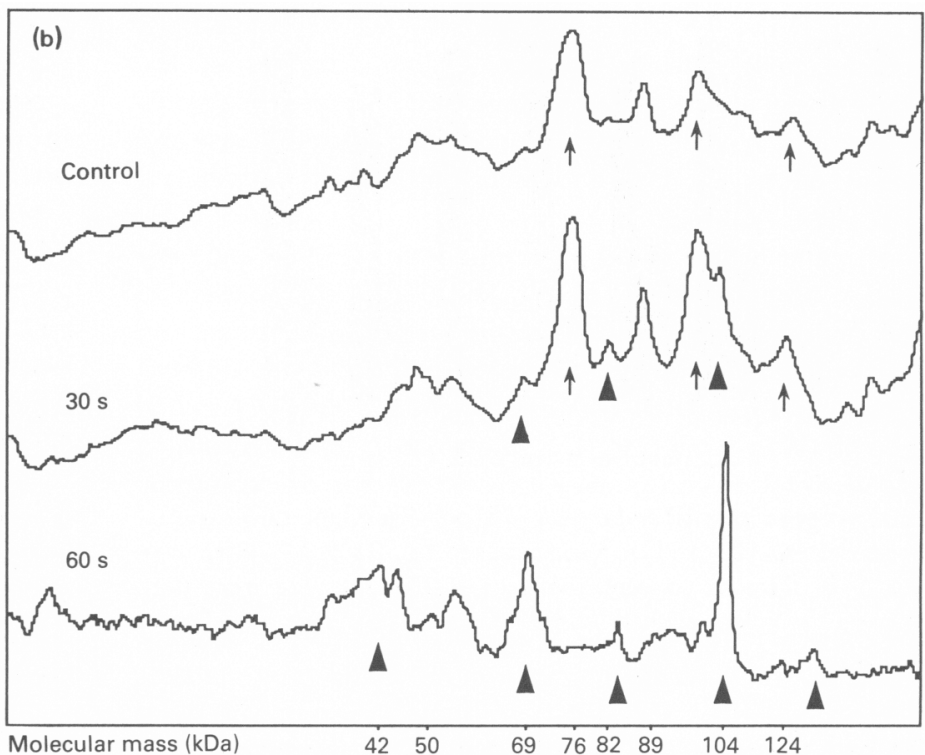

Fig. 4. Synthesis profile of $\left[{ }^{35} \mathrm{~S}\right]$ methionine-labelled polypeptides from control and UV irradiated (30 $\mathrm{s}$ and $60 \mathrm{~s}$ ) in vitro matured oocytes incubated for $20 \mathrm{~h}$ after activation. (a) Autoradiograms obtained by one-dimensional SDS-PAGE; (b) densitometric reading of the polypeptide profiles obtained from the autoradiograms in (a). Arrows show the proteins that were absent in oocytes exposed to UV irradiation for $60 \mathrm{~s}$. Arrowheads show protein bands present exclusively in UV-irradiated oocytes.

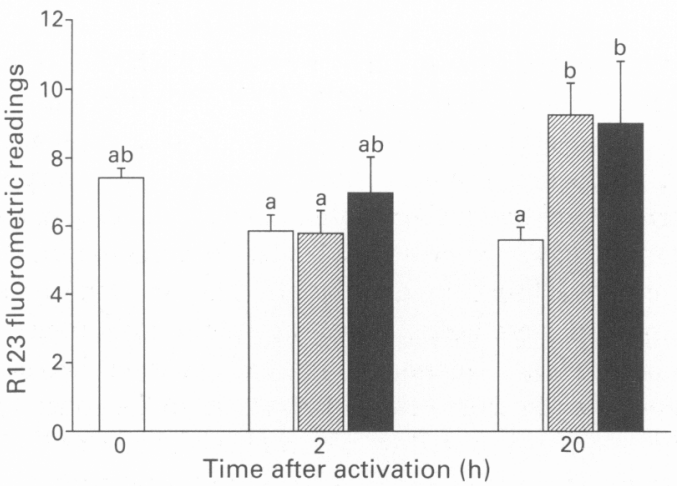

Fig. 5. Fluorometric monitoring of mitochondrial membrane potential with the laser dye rhodamine 123 (R123) in control ( $\square$ ), $30(\square)$ and 60 $(\mathbb{D}) \mathrm{s}$ UV irradiated individual oocytes at 0,2 and $20 \mathrm{~h}$ after activation. Values with different letters are significantly different $(P<0.05)$.

exposed for different periods to UV irradiation are substantially affected. Effects were observed at the level of membrane integrity, such as lysis, FDA accumulation and methionine uptake, and also at the intracellular level, such as quantitative and qualitative changes in protein synthesis and mitochondrial activity. Although some of the effects were less severe in oocytes exposed to $30 \mathrm{~s}$ of UV irradiation, exposures for $60 \mathrm{~s}$ caused substantial changes to most aspects of membrane and intracellular viability analysed. These changes to the non-genomic components of the oocyte appear irreversible in most cases and are likely to be incompatible with normal development.

At the level of the plasma membrane, oocytes exposed to $60 \mathrm{~s}$ of UV irradiation undergo changes to all aspects analysed by $20 \mathrm{~h}$ after exposure. Most lysed oocytes possessed a rough and fragmented membrane by $2 \mathrm{~h}$ and cytoplasmic leakage into the perivitelline space was noticed by $20 \mathrm{~h}$, suggesting a gradual deterioration of the membrane integrity. Nevertheless, the ability of oocytes to accumulate FDA within the cell increased with time and with longer exposure to UV irradiation. It is interesting to note from these results that effects of UV irradiation on plasma membrane appear to be different from those found after freezing and thawing of cells in which there is an accelerated loss of FDA possibly due to an increase in membrane permeability (McGann et al., 1988). According to Rotman and Papermaster (1966), as FDA is non-polar, it can readily pass into the oocyte where it is hydrolysed by esterases to yield polar fluorescein. Although polar fluorescein can cross the cell membrane, it does so less rapidly than the apolar FDA and, therefore, accumulates intracellularly. The effect of UV irradiation was to increase FDA accumulation in the non-lysed oocytes, which suggests either an increase in esterase activity or an alteration in the ratio between uptake and release of the apolar and polar compounds, respectively, by UV irradiation. The latter may have been due to a loss in the fluidity of the membrane due to lipid oxidation (Singh, 1989), leading to improper repair and closure of pores caused by the electric pulse. These effects may also have resulted in higher methionine uptake by irradiated oocytes.

Quantitative and qualitative changes to the intracellular protein synthetic activity were substantially affected by exposure to UV irradiation. Whereas uptake increased after UV irradiation, incorporation of radiolabelled methionine into protein in oocytes exposed for $60 \mathrm{~s}$ was reduced to $17 \%$ of that found in unexposed control oocytes. The patterns of proteins being synthesized were also markedly changed after irradiation. These changes are unlikely to be related exclusively to the repair of UV-induced damage, since not only did 'new' protein bands appear but also many stage-specific protein bands disappeared after prolonged irradiation, and suggest that changes to the endogenous developmental programme of protein synthesis 
also occur. Although some of these changes may have been caused by post-translational modifications, changes at the pretranslational level of cytoplasmic mRNA stores may also have been involved as shown to occur in irradiated mouse and Drosophila embryos (Masui and Pederson, 1975; Kobayashi and Okada, 1989).

Rhodamine 123 readings were significantly higher and very variable in oocytes exposed to UV. The mechanism for selective uptake of this dye into mitochondria resides in the attraction of the rhodamine cationic molecule toward the relatively high electronegative potential that exists across the mitochondrial membrane (Waggoner, 1979). It, therefore, provides means to assess the total proton motive force within the mitochondrial mass that may reflect ATP requirements in cells (Johnson et al. 1981). This positive correlation between rhodamine 123 fluorescence and the ATP requirement is supported by the strong mitochondrial staining of actively migrating or dividing cells and the reduced staining of confluent and progeria cells (Goldstein and Korczack, 1981). Although it is unclear why irradiated oocytes should produce high mitochondrial readings, increased energy requirement for the repair of membrane, or intracellular UV-induced damage or both are possibilities. However, UV irradiation has been shown to cause swelling and vesiculation of mitochondria, and fragmentation of germinal granules in Xenopus eggs (Ikenishi et al., 1974). Effects on the metabolic activity of mitochondria would probably be detected only at the later stages of embryonic development when there is an exponential increase in aerobic respiration (Rieger, 1992).

Finally, these findings clearly demonstrate that Hoechst 33342 staining should not be used for UV exposure periods of more than $30 \mathrm{~s}$. This level of exposure seems to be close to the threshold at which recovery from irradiation damage may be obtained. Cell viability should be assessed by other methods to determine the effects of UV irradiation at later stages of embryonic and fetal development. In Drosophila embryos, germ-line formation is blocked during embryogenesis in UVirradiated oocytes and fertility can be restored by injections of non-irradiated polar cytoplasm (Okada et al., 1974). This defect has been shown to be due to damage to the transcriptional ability of mitochondria and could be corrected by cytoplasmic injections of mitochondrial rRNA (Kobayashi and Okada, 1989). In mice, animals produced by nuclear transplantation carry mitochondrial DNA from both donor and recipient oocytes (Smith et al., 1991) and this finding emphasizes the need for care when using UV-irradiation for enucleating oocytes in the embryo cloning procedure.

The author would like to thank J. Bell for preparing the autoradiograms. This research was supported by CAAB, CORPAQ and NSERC.

\section{References}

Bondioli KR, Westhusin ME and Looney CR (1990) Production of identical bovine offspring by nuclear transplantation Theriogenology 33 165-174

Critser ES and First NL (1986) Use of fluorescein stain for visualization of nuclear material in living oocytes and early embryos Stain Technology 61 1-5
Goldstein S and Korczack LB (1981) Status of mitochondria in living human fibroblasts during growth and senescence in vitro: use of the laser dye rhodamine 123 Journal of Cell Biology 91 392-398

Gurdon JB (1960) The effects of ultraviolet irradiation on uncleaved eggs of Xenopus laevis Quantitative Journal of the Microscopic Society 101 299-311

Ikenishi K, Kotani M and Tanabe K (1974) Ultrastructural changes associated with UV irradiation in 'germinal plasm' of Xenopus laevis Developmental Biology 36 155-168

Johnson LV, Walsh ML and Chen LB (1980) Localization of mitochondria in living cells with rhodamine 123 Proceedings of the National Academy of Sciences USA 77 990-994

Johnson LV, Walsh ML, Bockus BJ and Chen LB (1981) Monitoring of relative mitochondrial membrane potential in living cells by fluorescent microscopy Joumal of Cell Biology 88 526-535

Kobayashi S and Okada M (1989) Restoration of pole-cell-forming ability to u.v.-irradiated Drosophila embryos by injection of mitochondrial RNA Development 107 733-742

Laemmli UK (1970) Cleavage of structural proteins during the assembly of the head of bacteriophage T4 Nature 277 680-685

McGann LE, Yang H and Walterson M (1988) Manifestation of cell damage after freezing and thawing Cryobiology 25 178-231

Masui $Y$ and Pederson RA (1975) Ultraviolet light induced unscheduled DNA synthesis in mouse oocytes during meiotic maturation Nature 257 705-706

Mohr LR and Trounson AO (1980) The use of fluorescein diacetate to assess embryo viability in the mouse Joumal of Reproduction and Fertility 58 189-196

Okada M, Kleinman IA and Schneiderman HA (1974) Restoration of fertility in sterilized Drosophila eggs by transplantation of polar cytoplasm Developmental Biology 37 43-54

Parrish JJ, Susko-Parrish JL, Leibfriedge-Ruthedge ML, Critser ES, Eyestone WH and First NL (1986) Bovine in-vitro fertilization with frozen thawed semen Theriogenology 25 591-600

Prather RS, Barnes FL, Sims MM, Robl JM, Eyestone WH and First NL (1987) Nuclear transplantation in the bovine embryo: assessment of donor nuclei and recipient cytoplasm Biology of Reproduction 37 859-866

Prather RS, Sims ML and First NL (1989) Nuclear transplantation in early pig embryos Biology of Reproduction 41 414-418

Rieger D (1992) Relationships between energy metabolism and development of early mammalian embryos Theriogenology 37 75-93

Robl JM and Stice SL (1990) Prospects for the commercial cloning of animals by nuclear transplantation Theriogenology 31 75-84

Rotman B and Papermaster BW (1966) Membrane properties of living mammalian cells as studied by enzymatic hydrolysis of fluorogenic esters Proceedings of the National Academy of Sciences, USA 55 134-141

Singh A (1989) Chemical and biochemical aspects of activated oxygen: singlet oxygen, superoxide anion, and related species. In Handbook on Free Radicals and Antioxidants in Biomedicine pp 17-28 Eds J Miquel, AT Quintanilha and HU Weber. CRC Press, Boca Raton

Smith LC and Wilmut I (1989) Influence of nuclear and cytoplasmic activity on the development in-vivo of sheep embryos after nuclear transplantation Biology of Reproduction 40 1027-1035

Smith LC, Silversides DW and Alcivar AA (1991) The development of reconstituted mouse zygotes with mitochondria of mixed origin Journal of Reproduction and Fertility Abstract Series 8 Abstract 17

Tsunoda Y, Shioda Y, Onodera M, Nakamura K and Uchida T (1988) Differential sensitivity of mouse pronuclei and zygote cytoplasm to Hoechst staining and ultraviolet irradiation Joumal of Reproduction and Fertility 82 173-178

Waggoner AS (1979) Dye indicators of membrane potential Annual Review of Biophysics and Bioengineering 8 47-68

Westhusin MW, Levanduski MJ, Scarborough R, Looney CR and Bondioli KR (1992) Viable embryos and normal calves after nuclear transfer into Hoechst stained enucleated demi-oocytes of cows Joumal of Reproduction and Fertility $95475-480$

Willadsen S (1986) Nuclear transplantation in sheep embryos Nature 320 63-65

Yang $X$ (1991) Embryo cloning by nuclear transfer in cattle and rabbits International Embryo Transfer Society News Letter 9 10-22

Yang X, Zhang L, Kovacs A, Tobback C and Foote RH (1990) Potential of hypertonic medium treatment for embryo micromanipulation: 11. Assessment of nuclear transplantation methodology, isolation, sub-zona insertion and electrofusion of blastomeres to intact or functionally enucleated oocytes in rabbits Molecular Reproduction and Development 27 118-129 